\title{
Posicionamento de gestores e lideranças de enfermagem diante dos erros divulgados na mídia
}

\author{
Behavior of nursing managers and leaders when errors are disclosed in the media \\ Posicionamiento de gestores y liderazgos de enfermería delante los errores divulgados en los \\ medios de comunicación
}

Como citar este artigo: Forte ECN, Pires DEP, Martins MMFPS Trindade LM, Schneider DG, Ribeiro OMPL. Posicionamento de gestores e lideranças de enfermagem diante dos erros divulgados na mídia. Rev Gaúcha Enferm. 2018;39:e20180039. doi: https://doi. org/10.1590/1983-1447.2018.20180039. a Universidade Federal de Santa Catarina (UFSC), Departamento de Enfermagem. Florianópolis, Santa Catarina, Brasil.

- Universidade Federal de Santa Catarina. Programa de Pós-graduação em Enfermagem. Florianópolis, Santa Catarina, Brasil.

Escola Superior de Enfermagem do Porto (ESEP). Porto, Portugal.

Universidade do Estado de Santa Catarina (UDESC), Departamento de Enfermagem. Florianópolis, Santa Catarina, Brasil.

Escola Superior de Saúde de Santa Maria (ESSSM). Porto, Portugal.

\section{RESUM0}

Objetivo: Analisar o posicionamento de gestores e lideranças de enfermagem acerca dos erros de enfermagem divulgados na mídia. Metodologia: Estudo qualitativo, retrospectivo, documental, coleta de dados realizada em jornais do Brasil e Portugal, entre 2012 e 2016. Análise realizada no Atlas.ti, utilizando a hermenêutica de Ricoeur fundamentada na Teoria do Agir Comunicativo de Habermas. Resultados: Gestores e lideranças destacam as condições de trabalho da enfermagem, e prestaram esclarecimentos quanto à ausência de supervisão e déficits na força de trabalho, seguiram com a abertura de sindicância interna, afastamento do cargo e demissão. As lideranças se posicionaram abrindo Processo Ético Disciplinar, realizando fiscalização, solicitando documentos e questionando acerca dos fatos, assim como repudiando algumas notas divulgadas.

Conclusão: As lideranças em enfermagem desempenham papel crucial no momento da divulgação de notícias que envolvem erros assistenciais, a fim de expor uma problemática complexa. Entretanto, isso não tem sido feito de forma eficiente.

Palavras-chave: Segurança do paciente. Enfermagem. Meios de comunicação. Liderança. Gestão de riscos.

\section{ABSTRACT}

Objective: To analyze the behavior of nursing managers and leaders when nursing errors are disclosed in the media.

Methodology: A qualitative, retrospective, documental study of the collection carried out in newspapers in Brazil and Portugal, between 2012 and 2016. Analysis performed at Atlas.ti, using a Ricoeur technique based on Habermas Theory of Communicative Action. Results: Managers and caretakers focused on the workforce, continuing with the opening of internal syndication, removal of position and dismissal. How to lead the discipline process, carrying out inspections, requesting documents and questioning about the facts, as well as repudiating some disclosed notes.

Conclusion: Leaderships in nursing played a crucial role in developing a complex problem strategy. However, this was not done efficiently. Keywords: Patient safety. Nursing. Communications media. Leadership. Risk management.

\section{RESUMEN}

Objetivo: Analizar el posicionamiento de gestores y liderazgos de enfermería sobre los errores de enfermería divulgados en los medios de comunicación

Metodología: Estudio cualitativo, retrospectivo y documental. Recolección de datos realizada en periódicos de Brasil y Portugal, entre 2012 y 2016. Análisis llevado a cabo a través del Atlas.ti, utilizando la hermenéutica de Ricoeur, fundamentada en la teoría del Actuar Comunicativo de Habermas.

Resultados: Gestores y liderazgos destacaron las condiciones laborales en enfermería y atestiguaron en relación a la ausencia de una supervisión y un déficit en la fuerza de trabajo, siguieron con una apertura de lo sindical internamente, destitución del cargo y despido. Los liderazgos se posicionaron abriendo un Proceso Ético Disciplinario, realizando una fiscalización, solicitando documentos y preguntando sobre los hechos, así como repudiando algunas notas divulgadas.

Conclusión: Los liderazgos en enfermería desempeñan un papel esencial en el momento de divulgar noticias que involucran errores de atención, con el fin de exponer una problemática compleja. Sin embargo, eso no ha sido realizado de forma eficiente. Palabras clave: Seguridad del paciente. Enfermería. Medios de comunicación. Liderazgo. Gestión de riesgos. 


\section{—INTRODUÇÃO}

A segurança do paciente e a qualidade dos cuidados em saúde tem se tornado um assunto recorrente na atualidade. As discussões em torno disso tiveram sua gênese no início deste século e apontam para a incidência de erros e falhas humanas decorrentes dos cuidados de saúde, em todos os âmbitos da assistência.

Os dados associados aos eventos adversos são alarmantes quando tratam das consequências desses incidentes, que geram aumento do tempo de internação, sequelas graves e morte de pacientes ${ }^{(1)}$. E, consequentemente, os custos gerados também são exorbitantes, podendo ser estimado um aumento de mais de $200 \%$ nos gastos quando há alguma intercorrência dessa natureza ${ }^{(2)}$.

Esses incidentes não são somente foco de estudos científicos e relatórios de organizações, eles se tornam constantemente, um atrativo para os meios de comunicação, em especial, quando o resultado gerado por esses incidentes está associado a consequências graves. Por isso, a mídia tem divulgado repetidas vezes situações de erros cometidos por profissionais de enfermagem, bem como outras informações que servem para compreender esses eventos, como as causas dos erros, a relação com a organização do trabalho de enfermagem, e as análises desses fatos que foram realizadas por gestores das instituições envolvidas e pelas lideranças de enfermagem organizações representativas da profissão.

Nessa divulgação em massa há sempre uma ressalva importante, haja vista que, nesse processo de produção de notícias existe uma busca desenfreada pelo novo, pelo impactante, pelo que chama atenção dos leitores, e assim pode se apresentar "apenas um retrato seletivo do real"(3:25), ameaçando a integridade do exercício profissional de enfermagem.

Os profissionais envolvidos nessas falhas estão sujeitos a alguma espécie de punição, e num estudo realizado em São Paulo, as punições sofridas por profissionais de enfermagem foram classificadas como grau leve (no caso da advertência verbal), grau moderado (advertência por escrito) e grau severo (com suspensão e demissão). Numa frequência muito menor aparece a capacitação que deveria ser muito mais utilizada para prevenir os incidentes futuros. Há ainda, a desconsideração de tais eventos, pois muito do que acontece segue subnotificado(4). O medo das punições dificulta a notificação, oculta ocorrências que ficam desconhecidas e, fatalmente, deixam de ser analisadas. A importância de notificar eventos adversos se deve ao objetivo de minimizar danos e aprender com esses $\operatorname{erros}^{(5)}$.

O trabalho da enfermagem é muito peculiar e é influenciado pelas formas de organização desse trabalho e, nesse processo complexo e dinâmico, uma diversidade de aspectos pode estar associada à causalidade dos erros. A área da saúde possui algumas fontes explícitas de erro humano que são bem conhecidas como a fadiga, as rotinas, as horas extras de trabalho, a sobrecarga, déficit e rotatividade de pessoal, dentre outras ${ }^{(6-8)}$. Além disso, esse trabalho em saúde e enfermagem compartilha as características de variabilidade e simultaneidade entre produção e consumo típicas do setor de serviços. Portanto, um cenário pleno de desafios e que precisa ser, constantemente, analisado com vistas a garantir a segurança de usuários e profissionais.

No ensejo de problematizar a questão do erro dentro das instituições de saúde e levantar aspectos importantes para a compreensão da temática, as notícias podem ser um veículo importante para o diálogo com a sociedade acerca desta questão. Assim, os textos jornalísticos podem se constituir em fontes preciosas de informação, desde que essas informações abranjam a complexidade dessa problemática, para compreender as razões pelas quais determinados eventos ocorrem, e desta forma, proteger a sociedade das falhas derivadas dos cuidados de enfermagem, e proteger os profissionais de enfermagem, ao manifestar-se acerca dos casos noticiados.

Com base no exposto, este estudo tem como questão de investigação: De que modo gestores e lideranças de enfermagem se posicionaram acerca dos erros de enfermagem divulgados na mídia no Brasil e em Portugal. Sendo assim, teve como objetivo analisar o posicionamento de gestores e lideranças de enfermagem acerca dos erros de enfermagem divulgados na mídia no Brasil e em Portugal. A posição das lideranças pode indicar caminhos a percorrer e melhor analisar esse problema, tão importante no cenário atual da saúde.

\section{METODOLOGIA}

Pesquisa documental, retrospectiva, interpretativa, de abordagem qualitativa, com a coleta de dados realizada em 2016 nos jornais de grande circulação em dois países, Brasil e Portugal, nas publicações feitas entre 2012 e 2016, por entender que esse período compreende as notícias mais recentes. Os jornais utilizados como fonte neste estudo, foram os considerados de grande circulação nacional ou por região em cada país. $O$ acesso às notícias se deu por meio da clipagem ou por assinatura temporária.

As notícias foram selecionadas a partir do uso dos termos: erros, enfermagem e erro médico. Todas as notícias encontradas que atenderam o critério de pré-seleção (tratar de erro exclusivamente de enfermagem) foram utiliza- 
das. As notícias selecionadas foram agrupadas no software Atlas.ti, para organização e codificação.

O referencial teórico adotado para esta pesquisa é a teoria da ação comunicativa de Jürgen Habermas ${ }^{(9)}$, na qual a comunicação não se reduz somente ao que é dito ou escrito, mas também se transforma em ação, pois é através desta que os indivíduos interagem com os outros num vai e vem argumentativo. Sendo assim, a comunicação midiática é ação, principalmente por expressar opiniões e fazer parte de um continuum na formulação de opinião e de ideias.

A análise dos textos foi realizada obedecendo aos passos da hermenêutica de Paul Ricoeur ${ }^{(10)}$, sendo a primeira etapa os procedimentos de leitura, com a identificação dos códigos de significados primariamente encontrados. A seguir a identificação dos possíveis sentidos permitiu que unidades de análise fossem associadas a outras partes do texto e em busca de novos significados. Por fim, a apropriação conferiu maior sentido aos textos analisados e possibilitou a formação de unidades temáticas.

A apropriação possibilitou a formulação de três categorias temáticas que revelam as condutas realizadas por gestores de enfermagem de serviços de saúde nos dois países, e de lideranças de enfermagem do Conselho Federal (COFEN) e Regionais de Enfermagem (COREN), Sindicatos e Ordem dos Enfermeiros de Portugal (OE), os quais manifestaram-se pelos jornais no período estudado.

Por questões relacionadas à ética, omitiram-se os dados relacionados com a identificação de profissionais, pacientes vítimas de erros, instituições, jornalistas que escreveram a matéria e jornais, evitando exposições ainda maiores, como preconizado pelas normas e diretrizes atuais que discorrem sobre a ética em pesquisa com seres humanos. Portanto, os trechos selecionados dos jornais estão identificados com a letra J, seguido da letra inicial de cada país e região, e uma numeração cardinal correspondente à ordem em que foram inseridas no software de análise de dados.

\section{口ESULTADOS E DISCUSSÃO}

Foram 112 notícias analisadas em que predominou os erros relacionados com a administração de medicamentos, os enfermeiros foram a maioria dos profissionais envolvidos e as consequências para os pacientes, na maior parte das notícias, resultou em morte, com especial particularidade, em crianças. $O$ ano com maior número de ocorrências foi 2012. Destas, foram encontradas 58 notícias com informações referentes ao posicionamento das lideranças de enfermagem relativos aos erros noticiados.

O predomínio de enfermeiros nas notícias analisadas pode ser explicado por duas razões: a primeira se refe- re à escolha por Portugal como fonte de dados, onde só compõe a força de trabalho de enfermagem, enfermeiros diplomados; a segunda pode estar relacionada à Lei do Exercício Profissional de Enfermagem no Brasil, em que consta a supervisão e a responsabilidade técnica dos enfermeiros de toda a equipe de enfermagem, ou seja, os enfermeiros respondem aos incidentes juntamente com suas equipes de enfermagem. Ademais, a mídia repassa as informações tendo como base o senso comum, o qual não diferencia a categoria de Enfermagem, que no Brasil é composta por Enfermeiros, Técnicos e Auxiliares de Enfermagem.

Nos meios de comunicação, em especial, na mídia jornalística, existem duas maneiras de versar sobre a saúde: "uma em que os assuntos são apresentados de maneira crítica, opinativa e polêmica", e outra em que o material é produzido e contextualizado"a partir de seu caráter factual, isto é, quando os assuntos são tratados a partir dos acontecimentos que irrompem entropicamente na superfície social e, ao invés de enunciados, são anunciados na esfera pública"(11:77).

\section{Um momento oportuno para pedir socorro}

Os textos jornalísticos analisados revelaram que os gestores das instituições envolvidas nos incidentes de erros noticiados, bem como as organizações representativas, se manifestaram a respeito, especialmente, acerca das condições de trabalho que os profissionais de enfermagem se deparam cotidianamente. As informações repassadas pelos jornais foram caracterizadas como um pedido de socorro, com vistas a dar mais visibilidade a problemas estruturais e de organização do trabalho.

A equipe de gerência de risco do [nome da instituição] e a comissão de óbitos neonatais do hospital já estão avaliando todos os métodos do setor, inclusive os processos de atendimento de pacientes e a sobrecarga de trabalho devido à falta de enfermeiros, conforme também avaliou a presidente do Conselho Regional de Enfermagem (JBSC1). [negrito da notícia] [Erro em procedimento que levou a morte um bebê de 40 dias].

O Coren afirma ainda, em nota, que o [nome da instituição] foi fiscalizado pelo órgão, que detectou inúmeras irregularidades, entre as quais superlotação de pacientes e falta de pessoal capacitado para atendimento na enfermagem (JBPR3). [Erro de medicação, troca de vias em que a alimentação foi administrada por via endovenosa que acarretou na morte de uma idosa]. 
Frente aos casos de erros de profissionais de enfermagem que causaram a morte das duas idosas, o Conselho Federal de Enfermagem (Cofen) afirmou em nota, nesta segunda-feira, que "por uma decisão da Justiça brasileira, os Conselhos de Enfermagem não podem fiscalizar as escolas e cursos superiores de enfermagem no país". A assessoria do Conselho Regional de Enfermagem informou que a atribuição é responsabilidade da Secretaria do Estado de Educação, no caso de cursos técnicos, e do Ministério da Educação, quando se trata de cursos superiores (JBPR5). [Erro de medicação, troca de vias em que a alimentação foi administrada por via endovenosa que acarretou na morte de uma idosa].

Se é verdade a troca de doentes no momento da recolha de sangue para análise laboratorial, não é menos verdade que tal facto é só um episódio de um corolário de erros e más práticas profissionais, envolvendo instituições e profissionais de saúde, afirma o sindicato (JPMA1). [Erro por troca de bolsas de sangue].

O déficit na força de trabalho de enfermagem, com a consequente sobrecarga de trabalho é um problema constantemente visto nos estudos que tratam da segurança, da qualidade e do próprio trabalho de enfermagem, e no quesito segurança, esses problemas tem forte relação com os eventos adversos. Evidências empíricas têm revelado que a falta de dimensionamento adequado de profissionais de enfermagem está intimamente ligada à probabilidade de erros e de acidentes no trabalho ${ }^{(6,12)}$.

A carga de trabalho dos profissionais de enfermagem, no sentido de horas de trabalho requeridas, é caracterizada pelas necessidades de cada tipo de paciente e leva em consideração também outras atividades inerentes à assistência. Considera-se a quantidade média de pacientes assistidos diariamente (cada qual com necessidades específicas e graus de dependência variados) pelo tempo médio de assistência por paciente ${ }^{(13)}$. E, embora o ConseIho Federal de Enfermagem, no caso brasileiro, estabeleça parâmetros mínimos a serem seguidos para o dimensionamento adequado de profissionais, por meio da resolução $543 / 2017^{(14)}$, existem muitas dificuldades por parte da gestão dos serviços de saúde em cumprir com esses parâmetros, pois envolvem gastos com pessoal, um componente importante que se constitui em empecilho para a melhoria da assistência em saúde.

Em Portugal, o dimensionamento adequado de enfermagem deveria seguir as diretivas da Ordem dos Enfermeiros para o cálculo de dotações seguras que, por sua vez, seguem as recomendações da Sociedade Europeia de
Cuidados Intensivos e da Direcção-Geral da Saúde ${ }^{(15)}$. No entanto, esta é uma das principais lutas dos enfermeiros portugueses, as dotações de enfermagem no país são pouco conhecidas, e menos ainda, aplicadas por gestores das instituições de saúde ${ }^{(16)}$.

Outra questão, em especial no caso do Brasil, diz respeito à ausência de supervisão, que pode estar relacionada a problemas de dimensionamento de pessoal. A Lei do Exercício Profissional de Enfermagem vigente no país, 7.498/86, é muito clara ao estabelecer que as atividades de enfermagem devem ser supervisionadas, sempre, por um enfermeiro. Contudo, a presença de um enfermeiro em todos os setores de todos os serviços de saúde, nas 24 horas de assistência, também se caracteriza como um problema de difícil resolução, haja vista que o setor saúde, muitas vezes, não possui verba suficiente para garantir a presença do profissional enfermeiro durante toda a jornada de trabalho da equipe ${ }^{(14)}$.

A supervisão também precisa ser considerada quando se trata de estudantes em fase de formação teórico-prática, e nesse sentido, as escolas de enfermagem são responsáveis por garantir a supervisão de seus alunos por um enfermeiro apto para tal tarefa. No caso de Portugal, legalmente, a assistência de enfermagem é prestada somente por enfermeiros com formação superior. Um aspecto positivo em relação à qualificação dos profissionais de enfermagem daquele país, mas que também tem problemas em relação ao dimensionamento adequado para atender as necessidades de saúde da população.

Em dezembro de 2016, uma nota num dos principais jornais portugueses trouxe a informação de que os hospitais portugueses devem mais de 539 mil horas extraordinárias para os enfermeiros, o que corresponde a mais de 67 mil dias de folgas, ao mesmo tempo em que não há previsão para a contratação devido à limitação financeira ${ }^{(17)}$. Outro dado importante a se considerar é o alto índice de emigração dos enfermeiros portugueses. Em 2014, o número de enfermeiros que pediram licença para exercer as funções em outros países chegou à ordem 2850. Isso se deve, segundo a bastonária da $\mathrm{OE}$, à falta de oportunidades de emprego, somado à baixa remuneração e à falta de planos de progressão na carreira ${ }^{(18)}$.

Nos dois países, parece que os problemas relativos à quantidade de profissionais de enfermagem e a superlotação dos serviços de saúde, principalmente, no âmbito hospitalar, tem comprometido a segurança dos usuários, o que também foi relatado por outros autores ${ }^{(19)}$. As condições de trabalho de enfermagem juntamente com a superlotação dos serviços, em especial, dos hospitais públicos, fomentam a visão negativa da sociedade com relação à assistência em saúde, por não se sentir segura nos ambientes hospitalares ${ }^{(20)}$. 
Outra questão importante levantada pelas lideranças se refere à fiscalização das escolas de enfermagem, e diz respeito aos erros cometidos por estagiários de enfermagem. No Brasil, a responsabilidade pela fiscalização das escolas técnicas de enfermagem é das Secretarias Estaduais de Educação, e os cursos superiores são acompanhados pelo Ministério da Educação. Essa dicotomia pode se constituir numa barreira para a qualidade do exercício profissional, tendo em vista que os Conselhos de Enfermagem deveriam participar ativamente das decisões referentes à formação dos profissionais de enfermagem.

No Brasil não houve nenhuma notícia, nos jornais estudados no período, relativas a erros envolvendo estudantes do ensino superior de enfermagem. E, em Portugal, não houve nenhuma notícia envolvendo estudantes.

\section{Segurança do paciente - uma forma de olhar a advocacia dos doentes}

Outras informações que partiram das lideranças de enfermagem dos serviços de saúde e das entidades representativas, se referem às condutas relativas à investigação dos casos de erros e às punições adotadas. Nesse sentido, as lideranças exercem papel crucial na defesa do direito das pessoas em receber cuidados de enfermagem de qualidade, em especial quando envolve negligência por parte dos profissionais. Advogar em prol do paciente tem o intuito de auxiliá-lo na obtenção de cuidados seguros e de qualidade ${ }^{(21)}$. Para que isso aconteça, gestores e lideranças precisam tomar decisões que contribuam diretamente para a garantia de cuidados seguros, sinalizadas na Figura 1.

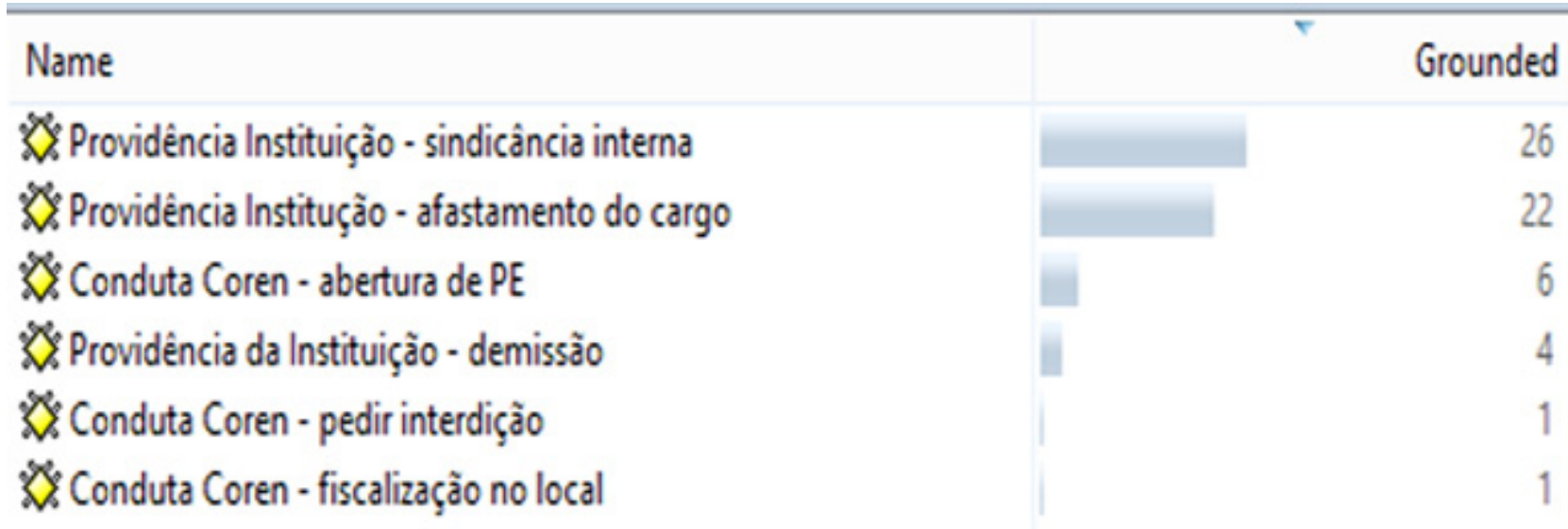

Figura 1 - Condutas e providências tomadas por gestores e lideranças de enfermagem frente aos erros noticiados. Florianópolis, SC, 2017.

Fonte: Dados da pesquisa retirados do Atlas.ti.

A abertura de sindicância administrativa interna é um ato comum nas instituições, pois visa reunir provas para a materialidade de um fato, comprovando ou não a culpa dos envolvidos e serve de medida cautelar para os órgãos de fiscalização, com isso pode poupar os acusados de serem culpados injustamente e evitar possíveis processos judiciais contra a instituição(22). Durante os processos de sindicância ou averiguações internas, é comum que o profissional envolvido no caso seja afastado de suas funções, até que se esclareçam todos os fatos.

As demissões que foram noticiadas, pelo que foi analisado nos textos, foram decididas após o resultado da sindicância. Entretanto, ao pensar nas questões de segurança do paciente, essa conduta vai de encontro à cultura não punitiva que deveria ser adotada pelas instituições de saú- de. Estudos atestam que as instituições devem evitar essas atitudes de cunho punitivo alegando que não traz benefícios para a segurança dos cuidados, e sim estimular uma cultura de educação para os profissionais de modo geral, sensibilizando-os para um olhar centrado no paciente(23).

Quanto às condutas dos órgãos representativos de fiscalização da enfermagem, nos dois países, estas seguiram, na maioria das vezes, para a abertura de Processo Ético Disciplinar, conduta comum diante de denúncias dessa natureza.

O Código de Ética dos Profissionais de Enfermagem brasileiro prevê que situações em que o profissional coloca em risco a vida do paciente ou não age de acordo com os deveres e responsabilidades ali estipulados, estão sujeitas a abertura de Processo Ético Disciplinar que será instruído 
de acordo com o Código de Processo Ético dos Conselhos de Enfermagem. Em Portugal, o processo disciplinar ocorre nos mesmos termos que o brasileiro e é regido pelo Código Deontológico do Enfermeiro.

O estudo de Schneider e Ramos ${ }^{(24)}$ que analisou elementos fáticos nos processos éticos disciplinares do Coren de Santa Catarina constatou que o motivo mais recorrente desses está relacionado com os erros de enfermagem (iatrogenias), e por sua vez, estão associados à imprudência, imperícia ou negligência dos profissionais. Por essa razão, a conduta dos Conselhos Profissionais é muito importante para o esclarecimento do fato em si e para promover a educação desses profissionais e de outros que possam participar desse processo.

Somente uma notícia retratou a necessidade de fiscalização no local do incidente.

Segundo o Coren, a direção do hospital não quis, num primeiro momento, informar o nome da funcionária que injetou a sopa. Sem a informação, "o Conselho ficou impossibilitado de saber se a funcionária tem registro profissional e se está habilitada para trabalhar na função, por isso terá fiscalização no local ainda essa semana" (JBSP9). [Erro de medicação, troca de vias em que a alimentação foi administrada por via endovenosa que acarretou na morte de um bebê].

A importância da fiscalização do exercício profissional não se resume aos profissionais habilitados, mas se estende para averiguação de pessoas que exercem ilegalmente a profissão, e com isso, visa proteger os pacientes de cuidados de enfermagem exercidos por pessoas que não possuem o conhecimento e a habilitação exigida para exercer a enfermagem. Nos dois países estudados a fiscalização tem se tornado cada vez mais efetiva com a finalidade de garantir melhores condições de trabalho e de atendimento para os clientes.

As condutas destacadas neste estudo direcionam o olhar dos leitores para a atuação dos gestores de enfermagem direcionada à punição dos profissionais, como forma de prevenção e promoção de cuidados seguros. Em contrapartida, as lideranças das entidades representativas, reforçam os problemas de ordem estrutural, como os déficits na força de trabalho, a sobrecarga, e a falta de capacitação e educação das equipes. Cuidados mais seguros e livres de danos requerem tomadas de decisão também seguras, no sentido de melhorar os processos organizacionais, educar permanentemente as equipes e instituir uma cultura de segurança que promova boas práticas cotidianamente, o que diverge completamente das ações de cunho punitivo(25-26). Nesse sentido, a literatura é vasta ao afirmar que as condutas praticadas pelas instituições de saúde diante de erros assistenciais devem ser voltadas à educação de seus profissionais e à revisão dos processos assistenciais $(9,10,25-27)$.

\section{"Nada sobre enfermagem sem a enfermagem": oportunidades para representar a profissão}

Os meios de comunicação possuem um papel de suma importância para dar visibilidade a determinados problemas. Na atualidade, com a velocidade com que as informações são produzidas e consumidas, a mídia pode ser caracterizada como uma ferramenta de dois lados. Tanto pode ser útil para a compreensão dos incidentes que ocorrem nas instituições de saúde, quanto pode encobrir a complexidade da realidade, mostrando apenas o lado apelativo e não esclarecedor.

A publicação de notas advindas das organizações representativas é uma oportunidade valiosa de defender os direitos dos profissionais de enfermagem, esclarecer dúvidas e dar voz a uma série de argumentações que podem desvendar acusações sem fundamento. Portanto, as lideranças de organizações representativas de enfermagem manifestaram-se diante dos fatos solicitando documentos do caso para análise, questionando acerca dos fatos para proceder à apuração, questionando a investigação em si e utilizando notas de repúdio. A Ordem dos Enfermeiros de Portugal emitiu somente uma nota, alegando que a profissional foi suspensa de suas atividades devido ao fato noticiado.

Em nota divulgada nesta quarta-feira, o Coren repudia a denúncia, e diz que ela "carece de fundamento". O comunicado afirma que [nome], apontada como técnica de enfermagem, não tem registro profissional no conselho. Além disso, não seria trabalho dos técnicos supervisionar os estagiários, mas dos enfermeiros. A nota relembra o laudo de exame cadavérico, assinado pelo perito legista: "De acordo com o laudo, o sangue colhido tinha aspecto normal. Também não foram evidenciados sinais de embolia gordurosa cardíaca e pulmonar, afastando a possibilidade de a paciente ter recebido café com leite por via venosa. O exame classifica como causas do óbito infecção pulmonar e urinária, patologias que não indicam ocorrência por injeção intravenosa de café com leite. As causas da morte não guardam relação com exame toxicológico de sangue", afirma trecho da nota (JBDF4). [Erro de medicação, superdosagem de medicamentos que acarretou na morte de duas crianças]. 
[presidente do Coren] diz que o conselho vem acompanhando "bem de perto" o fato, mas afirma que, a princípio, "parece que está sobrando (culpa) para apenas um profissional, uma profissão. Existe uma equipe dentro da unidade de saúde. Claro que se trata de um caso grave e quem tiver de responder, vai responder", afirma (JBPR1). [Enfermeiro acusado por omissão de socorro em uma Unidade de Pronto Atendimento, uma mulher de 38 anos morreu].

[presidente do Coren] também estranhou que a sindicância aberta para apuração da ocorrência esteja nas mãos de médicos e advogados. Se estão investigando problemas ocorridos com a enfermagem, é inconcebivel não haver um enfermeiro entre os membros do inquérito. $O$ presidente do Coren ainda questionou o fato de a Secretaria Estadual de Educação não ser notificada, uma vez que também é responsável pelo registro, autorização e reconhecimento dos cursos, enfim a formação dos estagiários (JBRJ3). [Erro de medicação, troca de vias em que a alimentação foi administrada por via endovenosa que acarretou na morte de uma idosa].

No contexto sinalizado, seria de grande valia que as instituições também expusessem os esclarecimentos pertinentes aos casos noticiados, de forma a evitar que a sociedade veja com maus olhos os profissionais de enfermagem. Dependendo da forma como são escritas essas notícias, há um toque de vilania que não leva em consideração os aspectos relevantes da organização do trabalho que promovem a segurança do paciente. Ao destacar nas notícias somente as ações punitivas, os gestores de enfermagem das instituições expõem esses profissionais a duras críticas da sociedade, sem trazer a reflexão dos fatores envolvidos num desfecho ruim.

Os erros de enfermagem e na saúde em geral, são complexos e determinados por muitos fatores que, geralmente, estão associados a outros tantos problemas de ordem estrutural e organizacional ${ }^{(28)}$. Nesse sentido, as representações da profissão têm o dever de atuar junto às instituições e outros órgãos competentes no esclarecimento dos fatos, na busca incessante de desfazer maus entendidos, e desmistificar algumas lacunas de interpretação que as notícias tendem a deixar.

A produção jornalística é uma maneira muito eficaz de tornar público determinados problemas da sociedade e, nesse contexto, precisa levantar diferentes informações, bem como diferentes pontos de vista sobre determinados assuntos, validando a informação e fornecendo subsídios para a compreensão da temática pelos olhares atentos da sociedade. A maior parte dos erros noticiados não é realizada de forma intencional, são erros assisten- ciais provenientes de múltiplos fatores que requerem análise cuidadosa de suas causas, com a finalidade de prevenir futuros incidentes. No entanto, os discursos midiáticos tendem a fomentar as emoções dos leitores para fins de comercialização das notícias ${ }^{(29)}$ e acabam por imprimir uma culpa nos profissionais de enfermagem sem a devida contextualização.

Foram detectadas duas lacunas importantes nessa pesquisa, a primeira é relativa à incipiência de notas por parte da Ordem dos Enfermeiros de Portugal e da Associação Brasileira de Enfermagem. Num período de 5 anos, com um corpus de pesquisa de 112 notícias que tratam de erros graves na assistência de enfermagem, estranha-se essa ausência. Pode se pensar em duas hipóteses: a falta de espaço dado pelos jornalistas para essas entidades ou pelas notas serem emitidas em outras formas de comunicação, como os sítios da internet, jornais próprios, rádio e televisão.

A outra lacuna está ligada ao número de notícias em que não houve nenhum posicionamento de quaisquer lideranças ou representação profissional, deixando em aberto as diversas possibilidades de compreensão do erro noticiado. Os limites considerados estão relacionados à coleta de dados que não considerou as reportagens de rádio e de televisão, e materiais dispostos na internet, como os espaços de expressão das organizações representativas.

\section{CONSIDERAÇÕES FINAIS}

As lideranças em enfermagem possuem papel crucial no momento da divulgação de notícias que envolvem erros durante a assistência, pois se tem a oportunidade de expor uma problemática complexa, que envolve diferentes mecanismos. Assim, as declarações noticiadas de posições dos gestores das instituições e das organizações representativas contribuem para que os leitores reflitam sobre as práticas da profissão enfermagem, sem impor uma culpabilidade imediata. Contudo, as informações provenientes de gestores e lideranças têm sido muito incipientes, haja vista que a maioria das notícias analisadas não possuía qualquer pronunciamento nesse sentido, o que pode ser explicado pela falta de espaço por parte da mídia e pelo receio de expor as instituições e os profissionais de enfermagem.

O enfrentamento do problema dos erros assistenciais requer uma discussão efetiva que direcione as ações relacionadas à formação dos profissionais de enfermagem, as condições de trabalho a que esses profissionais estão expostos no cotidiano das instituições de saúde e a forma como gestores das instituições e representantes da profis- 
são intervêm para a garantia da qualidade e da segurança no exercício profissional da enfermagem.

A luta por condições dignas de trabalho é incessante em ambos os países pesquisados e segue na direção de conseguir o mínimo desejado, especialmente, no que se refere ao quantitativo de profissionais, à jornada de trabaIho e à remuneração, que estão muito aquém do desejado para uma profissão de tal relevância social. Por isso, os meios de comunicação se constituem em oportunidade ímpar para dar voz tanto para os problemas relacionados aos erros de enfermagem, quanto para toda a conjuntura do trabalho que pode incidir sobre estes.

Os limites considerados estão relacionados à coleta de dados que não considerou as reportagens de rádio e de televisão, e materiais dispostos na internet, como os espaços de expressão das organizações representativas. Como contributo para enfermagem, este estudo serve para orientar pesquisadores, profissionais e gestores dos diversos níveis de assistência, da importância de fortalecer e valorizar a profissão diante de fatalidades expressas pelos meios de comunicação.

\section{DEFERÊNCIAS}

1. Forte ECN, Pires DEP, Padilha MI, Martins MMFPS. Nursing errors: a study of the current literature. Texto Contexto Enferm. 2017 Jun;26(2):e01400016. doi: https://doi.org/10.1590/0104-07072017001400016.

2. Porto S, Martins M, Mendes W, Travassos C. A magnitude financeira dos eventos adversos em hospitais no Brasil. Rev Port Saude Pública. 2010;(10):74-80. Volume temático.

3. Cardoso HS. Discurso criminológico da mídia na sociedade capitalista: necessidade de desconstrução e reconstrução da imagem do criminoso e da criminalidade no espaço público [dissertaçãoo]. Curitiba (PR): Universidade Federal do Paraná; 2011.

4. Fontana RT, Wolf J, Rodrigues FCP, Castro LM. Análise documental da mídia escrita sobre eventos adversos ocorridos na prática da enfermagem. Rev Enferm UFPE On Line. 2015;9(4 supl.):8103-10.

5. Ferreira MMM, Alves FS, Jacobina FMB. 0 profissional de enfermagem e a administração segura de medicamentos. Rev Enferm Contemp. 2014 jun;3(1):619.

6. Carlesi KC, Padiliha KG, Toffoletto MC, Henriquez-Roldán C, Juan MAC. Ocorrência de incidentes de segurança do paciente e carga de trabalho de enfermagem. Rev Latino-Am Enfermagem. 2017;25:e284. doi: https://doi.org/10.1590/15188345.1280.2841.

7. Rodrigues CCFM, Santos VEP, Sousa P. Segurança do paciente e enfermagem: interface com estresse e Síndrome de Burnout. Rev Bras Enferm. 2017 out [citado 2018 jun 09];70(5):1083-8. doi: https://doi.org/10.1590/0034-71672016-0194.

8. Lima Neto AV, Andrade FB, Morais SHM, Saraiva COPO, Medeiros SG, Santos VEP. Produção stricto sensu da enfermagem brasileira sobre segurança do paciente em unidades de terapia intensiva. Rev Min Enferm. 2017;21:e-1052. doi: https://doi.org/10.5935/1415-2762.20170062.
9. Habermas J. Teoria do agir comunicativo 1: racionalidade da ação e racionalidade social. São Paulo: WMF Martins Fontes; 2012.

10. Ricoeur P. Teoria da interpretação: o discurso e o excesso de significação. Lisboa: Ediçōes 70; 2016.

11. Oliveira VC. A comunicação midiática e o Sistema Único de Saúde. Interface (Botucatu). 2000;4(7):71-80. doi: https://doi.org/10.1590/S141432832000000200006

12. Keers RN, Williams SD, Cooke J, Ashcroft DM. Causes of medication administration errors in hospitals: a systematic review of quantitative and qualitative evidence. Drug Saf. 2013;36:1045-67. doi: https://doi.org/10.1007/s40264-013-0090-2.

13. Fugulin FMT, Gaidzinski RR, Castilho V. Dimensionamento de pessoal de enfermagem em instituições de saúde. In: Kurcgant P (coordenadora). Gerenciamento em enfermagem. 2. ed. Rio de Janeiro: Guanabara Koogan; 2010. Cap. 10, p. 121-35.

14. Conselho Federal de Enfermagem (BR). Resolução Cofen 543/2017. Atualiza e estabelece parâmetros para o Dimensionamento do Quadro de Profissionais de Enfermagem nos serviços/locais em que são realizadas atividades de enfermagem [Internet]. Brasilia, DF; 2017 [citado 2017 jul 24]. Disponível em: http:// www.cofen.gov.br/resolucao-cofen-5432017_51440.html.

15. Ribeiro O, Vieira M, Cunha M, Dias A, Martins R. Gestão do tempo no planeamento de cuidados de enfermagem. Servir (Lisboa). 2016 [citado 2018 jun 13];59(4):7-11. Disponível em: http://repositorio.ipv.pt/bitstream/10400.19/4580/1/GEST\%C3\%830\%20D0\%20TEMP0\%20NO\%20 PLANEAMENTO\%20DE\%20CUIDADOS\%20DE\%20ENFERMAGEM.pdf.

16. Brito M. Portugal tem o rácio enfermeiro/ habitante mais baixo da OCDE [Entrevista com Ricardo Correia de Matos]. Correio da Feira. 2018 abr 23;Entrevista:6-7. Disponível em: https://www.ordemenfermeiros.pt/media/6341/ rcm_entrevistacorreiodafeira_23042018.pdf.

17. Maia A. Hospitais estão a dever mais de 67 mil dias de folga aos enfermeiros. Diário de Notícias [Internet]. 2016 dez 10;Saúde. Disponível em: http://www. dn.pt/portugal/interior/hospitais-estao-a-dever-mais-de-67-mil-dias-defolga-aos-enfermeiros-5544044.html.

18. Maia A. Emigram mais enfermeiros do que aqueles que as escolas formam. Diário de Notíias [Internet]. 2016 mar 30. Disponível em: http://www.dn.pt/ portugal/interior/emigram-mais-enfermeiros-do-que-as-escolas-estao-aformar-5100105.html?utm_source $=$ dlvrit\&utm_medium =facebook.

19. Cauduro GMR, Magnago TSBS, Andolhe R, Lanes TC, Dal Ongaro. Patient safety in the understanding of health care students. Rev Gaúcha Enferm. 2017;38(2):e64818. doi: https://doi.org/10.1590/1983-1447.2017.02.64818.

20. Magalhães AMM, Dall'agnol CM, Marck PB. Carga de trabalho da equipe de enfermagem e segurança do paciente - estudo com método misto na abordagem ecológica restaurativa. Rev Latino-Am Enfermagem. 2013 jan/fev;21(spe):146-54. doi: https://doi.org/10.1590/s010411692013000700019.

21. Cole C, Wellard S, Mummery J. Problematising autonomy and advocacy in nursing. Nurs Ethics. 2014 Aug;21(5):576-82. doi: https://doi. org/10.1177/0969733013511362.

22. Ferreira ALP. Sindicância. Um processo complexo e complicado dentro das empresas. Comunidade ADM [Internet]. 2012 jan 14. Disponível em: http://www. administradores.com.br/artigos/carreira/sindicancia-um-processo-complexoe-complicado-dentro-das-empresas/60972/.

23. Teixeira TCA, Cassiani SHB. Análise de causa raiz de acidentes por quedas e erros de medicação em hospital. Acta Paul Enferm. 2014;27(2):100-7. doi: https:// doi.org/10.1590/1982-0194201400019. 
24. Schneider DG, Ramos FRS. Nursing ethical processes in the State of Santa Catarina: characterization of factual elements. Rev Latino-Am Enfermagem. 2012 Aug;20(4):744-52. doi: http://dx.doi.org/10.1590/5010411692012000400015.

25. Lorenzini E, Santi JAR, Báo ACP. Patient safety: analysis of the incidents notified in a hospital, in south of Brazil. Rev Gaúcha Enferm. 2014 Jun;35(2):121-7. doi: http://dx.doi.org/10.1590/1983-1447.2014.02.44370.

26. Andrade LEL, Lopes JM, Souza Filho MCM, Vieira Júnior RF, Farias LPC, Santos CCM, et al. Cultura de segurança do paciente em três hospitais brasileiros com diferentes tipos de gestão. Ciênc Saúde Coletiva. 2018 jan;23(1):161-72. doi: https://doi.org/10.1590/1413-81232018231.24392015.
27. Correia TSP, Martins MMFPS, Forte ECN. Processos desenvolvidos por gestores de enfermagem face ao erro. Rev Enf Ref. 2017 mar;serIV(12):75-4. doi: https:// doi.org/10.12707/RIV16073.

28. Agência Nacional de Vigilância Sanitária (BR). Assistência segura: uma reflexão teórica aplicada à prática. Brasília, DF: Anvisa; 2017. Série Segurança do Paciente e Qualidade em Serviços de Saúde.

29. Biancovilli P, Machado GOC, Souza MVAR, Jurberg C. Imprensa versus opinião pública: 0 câncer na capa de cinco jornais brasileiros. Rev Bras Cancerol. 2016 [cited 2018 mai 07];62(2):111-20. Disponível em: http://www.inca.gov.br/ rbc/n_62/v02/pdf/03-artigo-imprensa-versus-opiniao-publica-0-cancer-nacapa-de-cinco-jornais-brasileiros.pdf.
- Autor correspondente:

Elaine Cristina Novatzki Forte

E-mail: elainecnforte@gmail.com
Recebido: 20.03.2018

Aprovado: 31.07.2018 